\title{
CRISIS AGRARIAS, MORTALIDAD Y ALIMENTACIÓN EN LA CIUDAD Y TERRITORIO DE BARCELONA, DURANTE LA ALTA EDAD MEDIA
}

\author{
JORDI GUNZBERG MOLL \\ Universitat Pompeu Fabra \\ (Barcelona)
}

\section{SUMARIO}

1. Introducción.- 2. Bibliografía, fuentes y metodología.- 3. Territorio y alimentación.- 4. Crisis de alimentación.- 5. Mortalidades violentas.- 6. Cronología, intensidad de las crisis y alturas de la población.- 7. Conclusiones.- Apéndice documental.

\section{INTRODUCCIÓN ${ }^{1}$}

Durante muchos años la historiografía ha centrado su estudio y análisis en el conocimiento de las crisis de mortalidad que se extienden por Europa a partir del siglo XIV. Las crónicas, los registros reales, los documentos privados así como otras fuentes históricas dan una idea precisa de la gravedad de las epidemias y hambrunas bajomedievales. Sin embargo, las

'Siglas más utilizadas: $\mathrm{ACB}=$ Archivo de la Catedral de Barcelona, $\mathrm{ADB}=$ Archivo Diocesano de Barcelona, ACA = Archivo Corona de Aragón, AM = Archivo de Montserrat. LA I = Liber Antiquitatum volumen I, RB I= Ramon Berenguer I, SEC=Santa Eulàlia del Camp, núm. $=$ numero.

"Anuario de Estudios Medievales", 30/2 (2000) 
mortalidades y crisis de alimentación ya fueron frecuentes durante la alta Edad Media. El interés por esta materia, cuyo estudio combina áreas tan dispares como la antropología, la geografía o la demografía, se ha ido acrecentando gracias a las aportaciones bibliográficas que sobre la alimentación se han publicado en los últimos años. Se ha de destacar que entre los siglos VIII y XI se producen grandes cambios en los modelos alimentarios de la población. Estas pautas prácticamente se mantendrán invariables a lo largo de la baja Edad Media.

Con independencia de la existencia de una mortalidad violenta, generada por continuas guerras y destrucciones, puede decirse que producción agraria, alimentación y mortalidad son tres aspectos sociales y económicos estrechamente vinculados. Desde épocas tempranas la producción agraria fue la base de la alimentación tanto de la ciudad como del territorio de Barcelona. Con frecuencia, su falta provocará crisis que generarán mortalidad. Ante esta realidad es importante estudiar el inicio de la cadena, observando por tanto con detalle el paisaje y la explotación agraria. Se trata de establecer un modelo de producción de alimentos, que para Barcelona será parecido a otros modelos mediterráneos, pero muy diferente al paisaje que se encuentra en las zonas del interior o de montaña.

El punto de partida de este estudio coincide con la conquista carolingia en el siglo IX. Se inicia en este momento una nueva etapa en la historia de la ciudad, cuyo protagonismo lo tendrán, primordialmente los pobladores cristianos. A partir de ahora se suceden incursiones musulmanas que marcarán violentamente los primeros siglos de la urbe. Con la destrucción que hace Almanzor en el año 985 finaliza una época dominada por las mortalidades violentas, iniciándose una nueva etapa mucho más identificada con las crisis agrarias. Durante los siglos XI y XII Barcelona experimenta un notable desarrollo. Los cambios urbanísticos y la construcción de nuevas iglesias dan a entender que se está ante un período de expansión demográfica que con altibajos se mantendrá hasta la llegada de las crisis bajomedievales, cuyo estudio y análisis traspasan el marco cronológico del presente artículo. 


\section{BIBLIOGRAFÍA, FUENTES Y METODOLOGÍA}

Se dispone de una abundante bibliografía sobre la historia de la alimentación durante la alta Edad Media². Se trata, en líneas generales, de

${ }^{2}$ Estudios centrados en territorios europeos: A. ABEL, Crisis agraires en Europe (XIIIe-XXe), Paris, 1973. A.M. BAUTIER, Pain et pattisserie dans les textes médiévaux latins antérieurs au XIIIe siècle, en "Manger et boire au Moyen Âge. Actes du Colloque de Nice (15-17 octobre 1982)", Nice, Faculté des lettres et sciences humaines, vol. I, 1984, pp. 33-65; J.O. BENOIST, Le gibier dans l'alimentation seigneuriale (XIe-XVe siècle), en "Manger et boire au Moyen Âge", citado, vol. I, pp. 75-84; P. BONNASSIE, Consommation d'aliments immondes et cannibalisme de survie dans l'Occident du Haut Moyen Âge, "Annales. Économies, Sociétés, Civilisations", 5 (Paris, septembre-octobre 1989), pp. 1035-1056. I. CONDÉS I SANGRENIS, Els aliments a la regla de Sant Benet. En "I Col·loqui d'Història de l'Alimentació a la Corona d'Aragó", Lleida, Institut d'Estudis Ilerdencs, 1995, pp. 421-427; G. DUBY, Economia rural y vida campesina en el Occidente medieval, Barcelona, Editorial Península, 1973; Ch. HIGOUNET, Les forêts de l'Europe occidentale du Ve au XIe siècle, "Settimane di Studio sull'Alto Medioevo", XIII, Spoleto, 1966, pp. 343-397; J-C. HOCQUET, Le pain, le vin et la juste mesure à la table des moines carolingiens, "Annales ESC", 3 (mai-juin, 1985), pp. 661-689. I. IMBERCIADORI, Vite e vigna nell'alto medioevo, "Settimane di Studio sull'Alto Medioevo", XIII, citado, pp. 307-342; A.B. MARTINO, La comida y la bebida en los tiempos carolingios, en "Manger et boire au Moyen Âge", citado, vol. II, 1984, pp. 183-195; P. MANE, L'alimentation des paysans en France et en Italie aux XIIe et XIIIe siècles à travers l'iconographie des calendriers (sculpture, fresques...), en "Manger et boire au Moyen Âge", citado, vol. I, 1984, pp. 319-333; M. MONTANARI, Alimentazione, cultura, società nel Medioevo, en "I Col ·loqui d'Història de l'Alimentació a la Corona d'Aragó", citado, pp. 21-37; M. MonTANARI, L'alimentazione contadina nell'alto Medioevo. Napoli, Liguori Editore, 1979; M. MONTANARI, Il ruolo della caccia nell'economia e nell'alimentazione dei ceti rurali dell'Italia del Nord. Evoluzione dell'alto al basso medioevo, en "Manger et boire au Moyen Âge", citado, vol. I, 1984, pp. 331-337; M. MONTANARI, El hambre y la abundancia. Historia y cultura de la alimentación en Europa, Barcelona, Editorial Crítica, 1992 N.J.G. POUNDS, La vida cotidiana: historia de la cultura material, Barcelona, Editorial Crítica; R.I. ROTBER- T.K. RABB, El hambre en la historia. El impacto de los cambios en la producción de alimentos y los modelos de consumo sobre la sociedad, Madrid, Editorial Siglo XXI, 1990; M. ROUCHE, Le repas de fête a l'époque carolingienne, en "Manger et boire au Moyen Âge", citado, vol. I, 1984, pp. 265-296; B.H. SLICHER VAN BATH, Le climat et les récoltes en haut Moyen Age, "Settimane di Studio sull'Alto Medioevo", XIII, citado, pp. 399-425.

Referente a los estudios centrados en la Península Ibérica: C. LALIENA CoRBERA, "Sicut ritum est in terra aragonensis": comidas rituales y formas de solidaridad campesina en el siglo XI, en "I Col-loqui d'Història de l'Alimentació a la Corona d'Aragó", citado, pp. 665-691; A.I. LAPEÑA PAÚL, Notas en torno al sistema alimentario en un monasterio altoaragonés en la Edad Media (El caso de San Juan de la Peña), en "La Mediterrània, àrea de convergència de sistemes alimentaris (segles V-XVIII)", Palma de Mallorca, Institut d'Estudis Baleàrics, 1996, pp. 379391. MARTÍNEZ SOPENA-J. CARBAJO SERRANO, L'alimentation des paysans castillans du XIe au XIIIe siècle d'après les "fueros", en "Manger et boire au Moyen Âge", citado, vol. I, 1984, pp. 335-347; A. SESMA MUÑOZ, Aproximación al estudio del régimen alimentario del reino de Aragón en los siglos XI y XII, "Homenaje a Don Jose María Lacarra de Miguel en su jubilación del profesorado. Estudios Medievales", Zaragoza, 1977, pp. 55-78.

Por último habría que hacer referencia a las investigaciones cuyo ámbito de estudio es Cataluña de forma general y Barcelona, en particular: J. BoLós, Aportació al coneixement de l'alimentació als segles X-XII, segons les deixes testamentàries, en "I Col-loqui d'Història de l'Alimentació a la Corona d'Aragó", citado, pp. 457-480; A.M. CARMONA I CORNET, Un tracta d'aliments del segle XII d'origen català de l'Arxiu Capitular de Tortosa, en "I Col-loqui d'Història de l'Alimentació a la Corona d'Aragó", citado, pp. 837-843; I. Ollich, P.J. 
investigaciones centradas en unas épocas y territorios determinados. Por desgracia casi no se ha escrito nada sobre las crisis agrarias acaecidas en Barcelona durante el período histórico que abarca entre la conquista de la ciudad por los carolíngios y los inicios de la baja Edad Media.

Un segundo grupo bibliográfico lo integran estudios referidos a la historia de Barcelona entre los siglos IX al XII. Comprende una bibliografía mucho más extensa que la anterior, donde pueden encontrarse algunas investigaciones sobre crisis de mortalidad ${ }^{3}$.

REYNOLDS, M. OCAÑA, M. DE ROCAFIGUERA, Experimentació arqueològica sobre sistemes de conreu medievals. Primers resultats del projecte de l'Esquerda, en "La Mediterrània, àrea de convergència de sistemes alimentaris (segles V-XVIII)", citado, pp. 153-168; A. RIERA MELIS, Sistemes alimentaris $i$ estructura social a la Catalunya de l'Alta Edat Mitjana, en "Alimentació i societat a la Catalunya medieval". Barcelona, CSIC, 1988, pp. 1-26; IDEM, Alimentació $i$ ascetisme a l'Europa occidental en el segle XII. El model cluniacenc, en "I Col-loqui d'Història de l'Alimentació a la Corona d'Aragó", citado, pp. 39-105; IDEM, Alimentació $i$ poder a Catalunya al segle XII. Aproximació al comportament alimentari de la noblesa, "Revista d'Etnologia de Catalunya", 2 (febrer 1993), pp. 8-21; IDEM, Senyors, monjos i pagesos: alimentació $i$ identitat social als segles XII $i$ XIII, Barcelona, Institut d'Estudis Catalans. Secció Històrico-Arqueológica, 1997; IDEM, El sistema alimentario como elemento de diferenciación social en la Alta Edad Media. Occidente, siglos VIII-XII, en "Representación de la sociedad en la Historia: de la autocomplacencia a la utopía", Instituto de Historia de Simancas. Universidad de Valladolid; F.J. RUEDA ROIGÉ, El mensari a l'Art Medieval Català: consideracions sobre aspectes lligats a l'alimentació, en "I Col-loqui d'Història de l'Alimentació a la Corona d'Aragó", citado, pp. 783-789.

${ }^{3}$ Hay un elevado número de estudios centrados en la Barcelona altomedieval: P. BANKS, The topography of the city of Barcelona and its urban context in eastern Catalonia from the third to twelfth centuries, University of Nottingham, 1980 (tesis doctoral inédita). Se ha publicado parcialmente en: L'estructura urbana de Barcelona, 714-1300, en "Història de Barcelona. La formació de la Barcelona medieval", Barcelona, Enciclopedia Catalana, Ajuntament de Barcelona, vol. 2, pp. 26-71; IDEM, The north-western gate of the city of Barcelona in the 11th and 12th centuries, "Cuadernos de Arqueología e Historia de la Ciudad", XVII (Ayuntamiento de Barcelona, 1977), pp. 117-127; IDEM, "Burgus", "suburbium" and "vilanova". The extramural growth of Barcelona before a.d. 1200, en "Actes del II Congrés d'Historia del Pla de Barcelona celebrat a l'Institut Municipal d'Història, 6 i 7 desembre de 1985". Barcelona, Ajuntament de Barcelona, 1990, pp. 107-133; IDEM, The inhabitants of Barcelona in 1145, "Acta Historica et Archaeologica Mediaevalia", 9 (Universitat de Barcelona, 1988), pp. 143-166; J.E. RuIZ DOMĖNEC, Las estructuras familiares catalanas en la alta Edad Media. Introducción al estudio de la formación y evolución de los sistemas de parentesco en la nobleza, el campesinado y los cuadros urbanos, "Cuadernos de Arqueología e Historia de la ciudad", XVI (Ayuntamiento de Barcelona, 1975), pp. 69-123; La sociedad barcelonesa en los siglos XI y XII, Universidad de Barcelona, 1973 (tesis doctoral inédita); El desarrollo de la economía monetaria. La crisis de los pequeños propietarios libres durante los siglos XI y XII en el condado de Barcelona, "Miscellania Barcinonensia", XXXVIII (Ayuntamiento de Barcelona, 1974), pp. 17-67; S.P.BENSCH, Barcelona et its rulers 1096-1291, Cambridge, Cambridge University Press, 1995; P. BONNASSIE, Catalunya mil anys enrera. Segles X-XI, 2 vols., Barcelona, Edicions 62, 1979-1981; F. CARRERAS y CANDI, Geografia General de Catalunya. La ciutat de Barcelona. Barcelona, s.d.; G. FELIU I MONTFORT, La toponimia del Pla de Barcelona al segle X, en "Actes del I Congrés d'Història del Pla de Barcelona, celebrat a l'Institut Muncipal d'Història, els dies 12 i 13 de novembre de 1982", Barcelona, Edicions la Magrana, 1984, pp. 101-112; Els inicis del domini territorial de la Seu de Barcelona, "Cuadernos de Historia Económica de Cataluña", 
Una de las razones por las cuales las crisis altomedievales tanto en Cataluña como en otros territorios europeos son mal conocidas es a causa de la pobreza informativa de los documentos. En todo caso, se dispone de un elevado número de fuentes que indirectamente permiten acercarse a esta problemática. Son mayoritariamente documentos privados: compraventas, usufructos, empeños y otras obligaciones, en los que se mencionan expresamente la crisis de subsistencia como la causa por la cual se establecen los

Barcelona, Facultad de Ciencias Económicas y Empresariales de la Universidad y del Instituto Muncipal de Historia de Barcelona (marzo 1976), pp. 45-61; M. FERNÁNDEZ, F.X. HERNÁNDEZ, A. SuÁREZ, M. TATJER, M. VIDAL, Passat i present de Barcelona (1). Materials per a l'estudi del medi urbà, Barcelona, Universitat de Barcelona. Col·lecció Pau Vila, núm. 4, 1983; A. GARCÍA ESPUCHE, M. GUARDIA BASSOLS, Espai $i$ societat a la Barcelona pre-industrial, Edicions de la Magrana. Ajuntament de Barcelona. Institut Muncipal d'Història, 1986.

Estudios centrados en la crisis de mortalidad más conocida como fue la destrucción de Barcelona en el año 985: J. BALARI JOVANY, Orígenes históricos de Cataluña, Instituto Internacional de Cultura romànica: Abadia de San Cugat del Valles, 1964, vol I, pp. 303-312; $\mathrm{P}$. BONNASSIE, Une famille de la campagne barcelonaise et ses activités économiques aux alentours de l'An Mil, "Annales du Midi", LXXVI (Toulouse, 1964), pp. 261-303; G. FELIU, Almansur, Barcelona $i$ Sant Cugat, "Acta Historica et Archaeologica Mediaevalia", 3 (Universitat de Barcelona, 1982), pp. 49-54; M. RoviRA I SolÀ, Notes documentals sobre alguns efectes de la presa de Barcelona per Al-Mansur (985). "Acta Historica et Archaeologica Mediaevalia", 1 (Universitat de Barcelona, 1980), pp. 31-53; J.E. RUIZ DOMÉNEC, Introducción al estudio del crédito en la ciudad de Barcelona durante los siglos XI y XII, en "Miscelania Barcinonensia", XIV/XLII (Ayuntamiento de Barcelona, 1974), pp. 17-33; M. ZIMMERMANN, La presa de Barcelona per Al-Mansur i el naixement de la historiografia catalana, en "Els orígens de Catalunya: emancipació política i afirmació cultural". Barcelona, Edicions 62, 1988, pp. 71-96.

Algunos articulos que tratan directa o indirectamente crisis agrarias barcelonesas altomedievales: P. BENITO MONCLús, Clergues "feudataris", la disgregació del patrimoni de la Seu de Barcelona $i$ els orígens del sistema beneficial (1091-1157), "Anuario de Estudios Medievales", 29 (Barcelona, 1999), pp. 105-119; J.P. CANO, Evolució recent del paisatge vegetal a l'àrea de Barcelona (segles VI-XX) a partir d'analisis pol-líniques de sediments marins del Delta del riu Besós, Universitat Autònoma de Barcelona (tesis doctoral inédita), 1994; S. RIERA MORA, Evolució del paisatge vegetal holocé al pla de Barcelona, a partir de les dades pol líniques, Universitat de Barcelona (tesis doctoral inédita) 1994. J.M. PALET-S. RIERA MORA, Transformacions del paisatge en època alt-medieval (s. X-XII) al sector de Montjü̈c-El port: una aproximació histôrico-geogràfica, en "La ciutat i el seu territori, dos mil anys d'història. Actes del II Col·loqui d'História de Barcelona. Barcelona, octubre 1993, vol I, pp. 181-194; J.E. RUIZ DOMENNEC, The urban origins of Barcelona: agricultural revolution or commercial development? , "Speculum", LII (Cambridge, Massachusetts, 1977), pp. 265-286 IDEM, El sentido de la riqueza en el condado de Barcelona en el siglo XI. Notas para su estudio, "Miscellania Barcinonensia", XIV/XLI (Ayuntamiento de Barcelona, 1975), pp. 49-60; IDEM, Introducción al estudio del crédito en la ciudad de Barcelona durante los siglos XI y XII, Miscellanea Barcinonensia", XIV/XLII (1975), pp. 17-33; IDEM, El origen del capital comercial en Barcelona. "Miscellania Barcinonensia", XI/XXXI (1972), pp. 55-88; IDEM, Solidaridad familiar y organización de clanes en la ciudad de Barcelona en los siglos XI y XII, "Miscellanea Barcinonensia", XV/XLV (1976), p. 726; R. VIADER, Autour d'une practique juridique: les contrats agraires des archives captitulaires de Barcelona (XIe-XIIIe siècle), "Acta Historica et Archaeologica Mediaevalia", 1617 (Universitat de Barcelona, 1995-1996), pp. 147-165.

Otras crisis: A. AULESTIA Y PIJOAN, Barcelona ressenya històrica, Barcelona, 1976; J.E. RUIZ DOMĖNEC, La ciudad de Barcelona durante la Edad Media: De los orígenes a la formación de un sistema urbano, "Quaderns d'Arqueologia i Història de la Ciutat", XVIII (Barcelona, 1980), pp. 69-97. 
pactos entre las partes ${ }^{4}$. En menor medida se puede completar la información a través de las crónicas, si bién sólo dan una información muy esquemáticá. Cierra el capítulo de fuentes los datos aportados la epigrafía y la arqueología ${ }^{6}$.

Para determinar las crisis y su posible intensidad, se ha seguido como metodología la información que directa y explícitamente aparecen en los documentos privados. En menor medida se ha utilizado la valoración que de las hambrunas hacen las crónicas.

Se ha seleccionado como unidad de referencia el año en que tiene lugar las crisis. Para ello es necesario identificar primero las fechas, para después analizar su clase e intensidad. Se ha de decir que, debido a la falta de una documentación apropiada, es difícil establecer comparaciones entre las intensidades.

Otra técnica para deducir años de malas cosechas y crisis de alimentación es utilizando la hipótesis ideada por Bonnassie y Ruiz Domènec.

${ }^{4}$ Se han publicado una serie de materiales documentales que nos han servido como referencia a la hora de identificar y analizar los años de crisis: J. ALTURO I PERUCHO, L'arxiu antic de Santa Anna de Barcelona del 942 al 1200. Aproximació històrico-lingüística, Barcelona, 1985. 3 volums; A. FÀBREGA I GRAU, Diplomatari de la Catedral de Barcelona: Documents del ss. IXXIII: anys 844-1260. Volum I: Documents dels anys 844-1000. Barcelona, Catedral de Barcelona, 1995; G. FELIU-J.M. SALRACH (dir.), Els pergamins de l'Arxiu Comtal de Barcelona de Ramon Borrell a Ramon Berenguer I, 3 vols., Barcelona, Fundació Noguera, 1999; J. MAS I DOMĖNECH, Rúbrica dels "Libri Antiquitatum" de la Seu de Barcelona, en "Notes històriques del bisbat de Barcelona", 4 vols., Barcelona, 1914-1915; P. PUIG I USTRELL, El monestir de Sant Llorenc de Munt sobre Terrassa. Diplomatari dels segles X $i$ XI, 3 vols., Barcelona, Fundació Noguera, 1995; A. UDINA, La successió testada altmedieval a Catalunya, Barcelona, Fundació Noguera, 1984.

${ }^{5}$ Concretamente, para este período podemos encontrar algunas referencias a crisis alimentarias como son el Cronicon Dertusense II y el Cronicon altera Rivipullense (a). J.L. VILLANUEva, Viage literario a las Iglesias de España, Madrid, 1806, vol. V, pp. 236-249; A. ALCOVERRO Y PERICAY, La Crònica General d'Espanya, Barcelona, Editorial Barcino.

${ }^{6}$ E. RIU I BARRERA, Notícia sobre enterraments barcelonins de l'alta Edat Mitjana, en "Necròloplis i sepultures medievals de Catalunya", "Acta/Mediaevalia", annex 1, Barcelona, 1982, pp. 177-201; J. VIVES, Inscripciones perrománicas barcelonesas, "San Jorge, Revista Trimestral de la Diputación de Barcelona", 47 (julio 1962), pp. 56-62; J.Ma MiLlés VAllicrosa, De epigrafia hebraico-catalana, "Cuadernos de Arqueología e Historia de la Ciudad", XIII (Barcelona, Ayuntamiento de Barcelona, Museo de Historia de la Ciudad, 1969), pp. 97-98. También de este mismo autor, Una nueva lápida hebraica, fragmentaria, hallada en Barcelona, "Cuadernos de Arqueología e Historia de la Ciudad", 10 (Barcelona, 1967), pp. 209212; J. VIGUÉ, El monestir romànic de Sant Pau del Camp, Barcelona, 1974; A. ELIAS DE MoLINS, Catálogo del Museo provincial de Antigüedades de Barcelona. Comisión provicial de monumentos de Barcelona, Barcelona, 1888; J. MAS, Lo fossar de la Seu de Barcelona y ses inscripcions funeràries, en "Notes Históriques del Bisbat de Barcelona", Barcelona, 1911; J. CANTERA-J.M ${ }^{\mathrm{a}}$ MILlÁS, Inscripciones hebraicas en España, Madrid, CSIC, 1956; M. y A. PREVOSTI, Restos humanos procedentes de una necrópolis judaica de Montjuich (Barcelona), "Trabajos del Instituto Bernardino Sahagún", 1951, pp. 65-148. E. VIVES, La població medieval catalana, Vic, Editorial Eumo, 1989. 
Para ellos en época de crisis agrarias los grupos humanos poco pudientes han de recurrir al préstamo de productos agrarios ${ }^{7}$. Por tanto la venta de bienes inmuebles o su permuta por bienes de consumo panificables como el trigo y la cebada puede considerarse como signo indicativo de dificultades. En todo caso se hace necesario compararlo con fuentes paralelas ya que consideradas individualmente puede no significar nada, o ser sólo una crisis personal o familiar, sin correspondencia con otros individuos o con un territorio.

\section{TERRITORIO Y ALIMENTACIÓN}

Ya se ha comentado la importancia que tiene una descripción detallada del paisaje como forma de acercarse a la producción alimentaria en la época altomedieval. En este sentido los investigadores han propuesto dos grandes modelos de consumo que indirectamente explican la evolución paisajística de un territorio.

G. Duby centra su atención en la necesidad de cultivar cereales. El pan se convierte desde épocas muy tempranas en el alimento base. Por tanto la dieta humana altomedieval se basa en el consumo de panificables. No duda en afirmar que los campesinos necesitaban cultivar cereales aunque el clima no fuera el más favorable ${ }^{8}$. Es en este contexto que desde épocas tempranas aparecen crisis de subsistencia debido a fluctuaciones climáticas, suelos mediocres y la utilización de prácticas agrarias que facilitaban el agotamiento prematuro de la tierra cultivable. Esta situación se incrementa a partir de los siglos XII y XIII, en que a los años de escasez les suceden años de abundancia. Frente al cultivo de cereales el mundo forestal, reserva económica y fuente de provisiones, no adquirirá un papel predominante en la alimentación. Es más, el bosque medieval, con árboles escasos para la construcción, poco densos y degradados a causa de una explotación desordenada, sólo proporciona algunos materiales necesarios para la vida cotidiana, como la leña para el fuego, los hornos y los talleres. Todo el consumo alimentario basado en los huertos y en la carne no constituye más que el acompañamiento del pan?. En

${ }^{7}$ J.E. RuIz DoMÈNEC, Introducción, op. cit., p. 29.

${ }^{8}$ G. DUBY, Economia, op. cit., p. 21.

${ }^{9} \mathrm{G}$. DuBY, Economia, op. cit., p. 20. 
consecuencia, en aquellas zonas en las que hay un crecimiento humano excesivo, propiciado por una propiedad agraria munifundista, conduce con frecuencia a sus habitantes a la carestía.

M. Montanari ha remarcado la importancia que tiene el bosque y los matorrales tanto en la alimentación como en la economía del hombre altomedieval. El paisaje y la alimentación se basa en la explotación silvestre y pastoril. Hasta mediados del siglo XI el hombre medieval no pudo alimentarse exclusivamente del pan, en buena medida por la baja tasa de ocupación del espacio y por la existencia de una débil tecnología. Entre los siglos VI y X el paisaje europeo dibuja un mosaico contrastado entre espacios cultivados e incultos, al que corresponde un variado conjunto de actividades productivas: cultivo de cereales, huertos, caza, pesca, ganadería, etc. El sistema alimentario estaba muy diversificado con una mezcla de productos de origen vegetal y animal ${ }^{10}$. La supervivencia siempre era posible incluso con una explotación extensiva de terrenos incultos. En todo caso, podían producirse carestías forestales como también las había agrarias. Los trabajos de desbroce, roturación y colonización se intensificaron en todas las regiones europeas sobre todo a partir del siglo IX, gracias al impulso de iglesias, monasterios, señoríos y comunidades campesinas. Sólo por necesidad se talan árboles y se amplía el espacio cultivado. La deforestación del bosque se hizo con mucha cautela. En los siglos IX y X el ritmo se reduce y no será hasta mediados del siglo XI cuando la tala se intensifica manteniéndose este ritmo hasta finales del siglo XIII. A partir del año 1000 el pan ocupará un lugar central en la alimentación de las clases populares ${ }^{11}$.

Algunos autores sostienen que el sistema alimentario durante buena parte de la alta Edad Media se basaba en los recursos silvestres pastoriles encuadrados en estructuras agrarias. Por tanto las crisis en la producción de cereales no producen aún entre los campesinos unos efectos devastadores porque pueden ser neutralizadas a través del consumo de alimentos alternativos procedentes del bosque y de los yermos. De esta forma muchas hambrunas fueron superadas, antes del año 1100 , con productos aportados por la

${ }^{10} \mathrm{M}$. MONTANARI, El hambre, op. cit., p. 36.

${ }^{1 "}$ M. MONTANARI, El hambre, op. cit., p. 54 
ganadería o la caza. El sistema alimentario silvestre y pastoril constituye una auténtica válvula de seguridad frente al peligro de carestías ${ }^{12}$.

¿Qué situación se vive en la ciudad y el territorio de Barcelona entre los siglos IX y el XIII? ¿Qué modelo se ajusta mejor a su realidad? Hasta no hace muchos años el conocimiento del paisaje altomedieval barcelonés era prácticamente desconocido. De hecho, muchas valoraciones se basaban en la creencia, nunca demostrada, de un mundo boscoso consecuencia de los turbulentos años que abarcaron desde la caída del reino visigodo hasta la consolidación de la casa condal. En la actualidad puede hacerse una aproximación muy detallada y fiable de la evolución del paisaje vegetal en todo el territorio de Barcelona, gracias a los datos aportados por la ciencia polínica ${ }^{13}$.

Según estos datos, entre los siglos VII y VIII, hubo un incremento de los incendios que territorialmente abarcaron desde el Maresme hasta el Penedès ${ }^{14}$. Significaron la implantación de una gran deforestación de abasto regional que propició una auténtica ruptura en los sistemas de uso del medio. Los cambios ponen de manifiesto la pérdida de la actividad agrícola y el desarrollo de una labor ganadera. Si bien a partir del siglo VIII la frecuencia de los incendios y las deforestaciones disminuyen, continuarán siendo un elemento perturbador con un nuevo incremento durante los siglos X y XII. Por tanto, se produce entre los años 801 hasta 1000 una grave destrucción de la masa forestal y una degradación del medio vegetal. Con ello el paisaje muestra un proceso erosionador que dará lugar a la aparición de planas délticas en el territorio de Barcelona ${ }^{15}$.

Esta situación no será irreversible, pues entre los siglos XI y XII se produce una pequeña regeneración del bosque, probablemente a consecuencia de la restricción de las actividades pecuarias ${ }^{16}$. Esta mínima regeneración será paralela a la reducción de la explotación ganadera y a la expansión de la actividad agrícola, centrados en los cereales, el olivo, el cáñamo y la viña.

\footnotetext{
${ }^{12}$ A. RIERA MELIS, Sistemes, op. cit. También El sistema, op. cit., p. 52 y ss.

${ }^{13}$ S. RIERA MORA, Evolució, op. cit.

${ }^{14}$ S. RIERA MORA, Evolució, op. cit., p. 262

${ }^{15}$ S. RIERA MORA, Evolució, op. cit., p. 377.

${ }^{16}$ S. RIERA MORA, Evolució, op. cit., p. 359.
} 
En el territorio de Barcelona, el período comprendido entre la ocupación musulmana, la conquista carolingia y el siglo $\mathrm{X}$, aparece una población rural dispersa. A finales del siglo XI e inicios del siglo XII, se produce la gran expansión de la viña, mientras que habrá que esperar hasta los siglos XII y XIII para ver la propagación de los olivos ${ }^{17}$.

Los datos polínicos muestran que durante los siglos VI y VII se manifiesta en el delta del río Besos una cierta expansión agrícola, concretamente de cereales y de olivos. Ésto no impide la existencia de un proceso de regeneración forestal y una disminución de los matorrales dedicados a la ganadería $^{18}$. A partir del siglo VIII, coincidiendo con una intensificación de la desforestación y la degradación del medio vegetal, la actividad agrícola ve reducida su importancia, mientras que se desarrolla una explotación ganadera intensiva. La agricultura mantiene su presencia sólo durante breves períodos de tiempo. Por tanto, con el desarrollo pecuario, el territorio comprendido entre los deltas de los ríos Besos y Llobregat se convierten en centros de pastos para el ganado ${ }^{19}$.

Referente a la viña, si bien la mayor parte de los historiadores ${ }^{20}$ han puesto de manifiesto que su expansión se origina en el siglo $X$ y se desarrolla durante el siglo XI, según las datos polínicos no se pueda hablar de cultivo extensivo antes del año 1100 . La expansión definitiva se produce a finales del siglo $\mathrm{XII}^{21}$. Se ha de decir que este análisis no coincide con los datos aportados por la documentación histórica. Según los contratos privados la viña tiene su máximo desarrollo entre los años 1060 y 1080, produciéndose después una caída en su producción ${ }^{22}$. Corrobora el hecho que entre los años 1050 y 1070 se incrementa el precio de la tierra dedicada a este cultivo, signo inequívoco de un desarrollo intenso ${ }^{23}$. El descenso de las rentas que experimentará la Seo a finales del siglo XI será una consecuencia de la caída de los

\footnotetext{
${ }^{17}$ J.M. PALET-S. RIERA, Transformacions, op. cit.

${ }^{18}$ J.P. CANO, Evolució, op. cit.

${ }^{19}$ S. RIERA MORA, Evolució, op. cit., p. 352.

${ }^{20} \mathrm{P}$. BONNASSIE, Catalunya, op. cit.

${ }^{21}$ J.P. CANO, Evolució, op. cit.

${ }^{22}$ Concretamente los estudios realizados por Bonnassie, Ruiz Domènec $y$, más recientemente, por Bensch y Viader.
}

${ }^{23}$ P. BonNASSIE, Catalunya, op. cit., II, p. 272. 
rendimientos económicos de la vinicultura, hecho que obligará a la institución a reorientar las inversiones y la producción ${ }^{24}$.

Los olivares inician su expansión hacia el año 1000, al igual que sucede en otros puntos del Mediterráneo, como el Norte de Africa, el Rosellón y la Provenza.

La explotación ganadera y los cambios del paisaje observados durante los siglos VII y VIII representan el primer modelo alimenticio de la población barcelonesa. El progreso de la ganadería se hace patente con la protección de determinados terrenos de pastos reservados para rebaños propios. Este fenómeno queda reflejado gracias a la gran multiplicación lingüística del termino ferragenals ${ }^{25}$. Su número y densidad será sobre todo mayor en la ciudad y sus alrededores, tanto extra como intra muros ${ }^{26}$. Esta situación se mantiene hasta el siglo XI, momento en el cual hay una reducción de las actividades pecuarias intensivas. A partir de este momento se extienden por todo el litoral las labores agrícolas (olivo, cereales y viña) con un cambio fundamental en la base económica que supone un nuevo modelo de alimentación.

En los inicios del siglo XI es cuando los cereales empiezan a ocupar un lugar central en la alimentación; el resto de comida sólo se considera accesorio: una simple guarnición que acompañaba el $\operatorname{pan}^{27}$. Los panificables son cada vez más necesarios en la dieta. Posiblemente porque se trata de un producto mucho más económico, aunque su consumo estará temporalmente limitado por el hecho que aún no existen demasiados lugares donde se pueda cultivar. En todo caso los cultivos han de hacer frente a una demanda cada vez mayor, consecuencia del desarrollo de una población demográficamente en expansión. Se da la circunstancia que a partir del siglo XI, el acceso al bosque resultará cada vez más difícil, por lo tanto, la caza y la ganadería ya no tendrán el lugar preeminente que tuvieron siglos antes.

\footnotetext{
${ }^{24} \mathrm{P}$. BENITO I MONCLÚS, Clergues, op. cit.

${ }^{25} \mathrm{La}$ traducción más ajustada sería campos de forraje. P. BonNASSIE, Catalunya, op. cit., I, p. 410. También se puede identificar como herrenal. L. RUBIO GARCíA, Documentos lingüísticos catalanes (s.X-XII), Murcia, Universidad de Murcia, p. 340.

${ }^{26}$ Se trata de parcelas muy valoradas ya que un ferragenal en Barcelona se vende en el año 1020 por 8 mancusos. AM. pergaminos Bages, núm. 1300.

${ }^{27}$ M. MONTANARI, El hambre, op. cit., p. 54.
} 
La montaña de Montjuïc sigue un desarrollo paralelo a otras zonas del territorio de Barcelona. La documentación muestra una progresiva explotación de la viña durante el siglo XI, hecho que indica una intensificación en su cultivo. Esta situación no se mantendrá mucho tiempo ya que en el siglo XII se produce una reducción importante de la explotación vinícola coincidiendo con el desarrollo de los olivos ${ }^{28}$.

\section{CRISIS DE ALIMENTACIÓN}

A la hora de localizar carestías y crisis alimentarias se ha señalar que los documentos pueden especificar tanto necesidades concretas de una persona o de un grupo reducido, como también gravísimas hambrunas extendidas a todo el territorio y a amplios colectivos. Entre las frases que dan a entender hambrunas generalizadas encontramos: "... in ipso anno quando fuit grande necessitas fame per totam nostram regionem"29. También: "... per plurimas fames, qui fuerunt in patria Barchinona"30. Se destaca asimismo: "... pro ipsa necessitate qui fuit in ipso anno quando homines exierunt de comitatu Barchinone et fuerunt in alias regiones"31.

Que las hambres y necesidades sean extensivas a otros vecinos también se citan en algunos documentos. Tal es el caso de Gerberga que junto a sus hijos Bernat, Arnau, Estefania y Guilia han de vender al sacerdote Pere Seniofret una casa situada en la ciudad de Barcelona, bajo las torres de Berenguer Fruiany, por un precio de 21 mancusos de oro, a causa de: "... facimus autem hec propterea quia cogit nos magna famis necessitas atque

\footnotetext{
${ }^{28}$ Mientras que durante el siglo XI de 65 documentos se citan 52 referencias, o sea un 80 por 100; en el siglo XII de 46 documentos aparecen únicamente 22 noticias, es decir se ha reducido a un 48 por 100 . Se trata de un dato estadístico que puede mostrar la menor importancia que tuvo la viña durante el siglo XII en la montaña de Montjuïc, y por tanto puede ser perfectamente extrapolable a otras zonas del territorio de Barcelona. Otro ejemplo que muestra la caída de ventas de viñas es que las transacciones de tierras destinadas a la vinicultura disminuye en un 60 por 100 en el año 1080, hasta un 26 por ciento a principios del siglo XII. Cfr. S.P. BENSCH, Barcelona, op. cit., p. 110; J.M. PALET I MARTíNEZ-S. RIERA I MORA, Transformacions, op. cit.

${ }^{29} \mathrm{ACA}, \mathrm{RB}$ I, núm. 246

${ }^{30} \mathrm{ACA}, \mathrm{RB}$ III, núm. 191.

${ }^{31} \mathrm{ACB}$, LA I, núm. 521.
} 
inopia, et cuncte nostre utilitatis nobis profuture indigencia atque penuria universis nostris vicinis et terris omnibus valde nota" ${ }^{132}$.

Las necesidades alimenticias llegaron a obligar a algunos habitantes a comer hierbas de los campos, tal como sucede con Ermetrui y su hija Bonadona que, a causa de sus necesidades, se ven obligadas a vender un herrenal a Gerbert, presbítero, ya que: "...non abent nichilque manducare neque bibere nisi erbas de ipsos campos ${ }^{133}$.

En ocasiones, la necesidad y el hambre empujan a vender una casa situada en el suburbio de Barcelona, tal como lo hace Petronila a Ramon Llopart y al clérigo Bernat Otger: "...anc namque vendicionem necessittate famis vobis facio, ne ego et filii mei fame intoleribili moriamur ${ }^{134}$.

Este empeño de solucionar las necesidades alimenticias del propietario y de su familia es la que más frecuentemente se señala en los documentos. Guibert Bonfill y su mujer Nevia han de vender una tierras a Ardencia a causa de: "...propter inopiam famis ut unde vivamus nos et infantes nostri" ${ }^{135}$.

También entra dentro de esta dinámica la venta de una viña que realizan los hermanos Honofret, Guifret i Domènec Bernat a Pere Umbert: "...deinde cogente nimia necessitate ${ }^{1136}$.

La posible intensidad del hambre y su vinculación con la pobreza también son mencionados en algunos documentos: "...in maxima necessitate famis" ${ }^{137}$, o "...pro necessitate fame et inopie" ${ }^{138}$.

Asimismo aparece escrito el término carestía, entendido como un período de tiempo en que faltan alimentos, situación que se vive cuando Ermensenda, viuda de Pere Bruny y sus hijas Guilerma, Saurina, Maria y Joana deben vender una tierras. Mencionan que lo hacen: "...por magna necessitate famis et pauperitatis quam patimur tempore carestie ${ }^{139}$.

\footnotetext{
${ }^{32} \mathrm{ACB}$, LA I, núm. 286.

${ }^{33} \mathrm{ACB}$, LA II, núm. 247.

${ }^{34} \mathrm{ACB}, 1-4-311$.

${ }^{35} \mathrm{ACB}$, LA I, núm. 496.

${ }^{36} \mathrm{ACB}, \mathrm{LA}$ IV, núm. 121

${ }^{37} \mathrm{ACB}, \mathrm{LA}$ II, núm. 725.

${ }^{38} \mathrm{ACB}$, LA I, núm. 874.

${ }^{39} \mathrm{ACB}$, LA I, núm. 1026.
} 
Se han analizado en los últimos años las causas de las crisis alimentarias durante la alta Edad Media ${ }^{40}$. Los textos hablan de 29 hambres generales europeas entre los años 750 y 1100. En Francia, el mayor número de carestías se producen durante el siglo XI. Tanto es así que incluso se dieron casos de auténtica antropofagia en muchos poblados ${ }^{41}$. Se citan graves carencias durante los años 1032-1033 en Francia y 1094 en el Imperio. A este nivel se opina que cuanto mayor es la dependencia de las cosechas cerealísticas, más grave son los impactos climáticos sobre una población que está creciendo ${ }^{42}$.

No puede hablarse de crisis de alimentación sin referirse a la evolución histórica de la Barcelona del siglo XI. Recientemente, diversos estudios han puesto de manifiesto que, hacia el año 1100 , se produce en la ciudad una grave crisis $^{43}$. Algunos investigadores remarcan la negativa incidencia económica y social que tuvo la reducción del cultivo de la viña, mientras que para otros hay una estrecha relación entre los orígenes de la crisis y la aparición de feudos eclesiásticos entre los años 1094 y $1098^{44}$. Además, en un contexto general de cambio, diferentes clérigos aprovecharon las dificultades de los habitantes para adquirir la propiedad de sus tierras ${ }^{45}$.

Bonnassie ha puesto de manifiesto como se incrementan los excedentes agrícolas a lo largo de los últimos 25 años del siglo XI, más concretamente de cereales y vino ${ }^{46}$. Siendo así, cabría preguntarse por qué son tan numerosos

${ }^{40} \mathrm{P}$. BonNASSIE, Consommation, op. cit.

${ }^{41}$ En los años 1032 y 1033, se extendió una carestía que devastó los territorios bizantinos, Italia, Galia e Inglaterra. Fue tan grande el hambre que los hombres tuvieron que comer animales muertos, raíces silvestres, plantas acuáticas y más adelante carne humana. Cfr. M. MONTANARI, El hambre, op. cit., pp. 48-49.

${ }^{42}$ M. MONTANARI, El hambre, op. cit., p. 50.

${ }^{43}$ Hay que señalar que esta crisis, que cronológicamente abarca los últimos 10 años del siglo XI y los primeros del siglo XII, había pasado desapercibida tanto a Ruiz Domènec como a Bonnassie. Ambos suponían que la revolución de la vinicultura, la irrigación del territorio de Barcelona, la aparición de una agricultura especializada, base de la acumulación inicial de capital y orígenes de la riqueza de Barcelona tuvo una continuidad ininterrumpida durante el XII. De hecho la caída de la vinicultura hacia el año 1080 pone en entredicho la tesis de Ruiz Domènec sobre el desarrollo de un mercado orientado hacia la producción hacia el año 1100 . Cfr. P. BONNASSIE, Catalunya, op. cit. J.E. RUIZ DOMĖNEC, La ciudad, op. cit y The urban origins, op. cit. op. cit.

${ }^{44}$ S.P. BENSCH, Barcelona, op. cit., pp. 85-121. También P. BENITO I MonClús, Clergues,

${ }^{45} \mathrm{P}$. BEnito I Monclús, Clergues, op. cit., pp. 116-117.

${ }^{46}$ P. BONNASSIE, Catalunya, op. cit., II, p. 409. 
los años de escasez. Además, este análisis se opone a los datos polínicos que manifiestan la gran expansión de la agricultura de cereales se desarrolla a partir de la segunda mitad del siglo XII.

En el siglo XI se observa un aumento del tipo de interés debido a que la demanda capital-dinero creció más rápidamente que la oferta, de forma que al extenderse la producción agrícola y el comercio, también se extendió su desarrollo sobre la base del sistema de crédito ${ }^{47}$. Por tanto, se produce una expansión económica en el territorio de Barcelona, siendo los presbíteros quienes realizan prestamos para el consumo, concretamente productos en especie, en épocas de malas $\operatorname{cosechas}^{48}$. Es lo que se conoce como los "préstamos del hambre"49.

Mientras en el siglo XI son muy numerosas las noticias de carestías, algunos autores mencionan que durante el siglo XII hay una cierta disminución $^{50}$. Los datos polínicos señalan que la gran expansión de la agricultura no se produce en el siglo XI sino en el siglo XII, momento en que las estructuras feudales comienzan a consolidarse ${ }^{51}$. Estos datos pueden ser corroborados siguiendo la evolución de los contratos agrarios durante los siglos XI al XIII ${ }^{2}$.

A la hora de analizar el papel de la viña a partir del año 1000 en el territorio de Barcelona, puede decirse que hay una cierta contradicción entre documentación y datos polínicos. En el siglo XI aparecen algunos hechos que hacen plantearse ciertas dudas sobre el alcance real de la vinicultura. Se trata en su mayoría de contratos pocos numerosos, privilegiados y específicos. En todo caso su gran desarrollo se produce entre los años 1060 y 1080. Dentro de la alimentación, el vino es un producto rico en calorías pero complementario de la dieta. Diversos estudios han manifestado el carácter especulativo y comercial que tiene este tipo de cultivo. Se ha de decir que la vinicultura responde más a una economía de demanda que a las exigencias del suelo y del

${ }^{47}$ RUIZ DOMÈNEC, Introducción al estudio, op. cit., p. 26.

${ }^{48} \mathrm{ACA}$, RB I, núm. 66.

${ }^{49}$ Término utilizado por P. BonNASSIE, Catalunya, op. cit. También J.E. RUIZ DoMÈNEC, Introducción al credito, p. 28.

${ }^{50} \mathrm{M}$. Montanari opina que en el siglo XII parece que disminuyen la frecuencia e intensidad de las hambres. M. MONTANARI, El hambre, op. cit., p. 50.

${ }^{51}$ S. RIERA MORA, Evolució, op. cit., p. 361. También. R. VIADER, Autour, op. cit.

${ }^{52}$ Concretamente, ha estudiado 550 actos desde los siglos XI hasta el XIII, conservados en el Archivo de Catedral de Barcelona. R. VIADER, Autour, op. cit. 
clima $^{53}$. Los años 1130 y 1140 marcan una disminución especulativa de la producción vinícola, incluso muchas viñas son abandonadas. En todo caso, las viñas están sólidamente implantadas desde el siglo anterior en las explotaciones campesinas. En Barcelona, su cultivo saturó el terreno preurbano, dándose además la circunstancia que son contratos penalizados con obligaciones ${ }^{54}$. En la explotación de las tierras de la catedral, los contratos redactados durante el siglo XI son pactados por familias concretas. No puede negarse que en el momento de máximo desarrollo de la vinicultura la ciudad experimenta una gran urbanización ${ }^{55}$. Algunos estudios manifiestan que, a causa del descenso del cultivo de la viña, se produce una recesión que prácticamente durará hasta el año $1140^{56}$. De hecho, cuando vuelva de nuevo la prosperidad con una economía en expansión, la producción de vino no se incrementará, sino que incluso declinará.

Durante el siglo XII habrá un cambio radical en el paisaje agrario. En la primera mitad del siglo, el cultivo de viñas decae significativamente respecto a la centuria anterior aumentando el desarrollo de masías, huertas y parcelas cultivables. Los huertos que van apareciendo en el territorio de Barcelona tienen un valor económico considerable. Es durante la segunda mitad del siglo XII cuando aparece este tipo de cultivo, aunque tendrá su máximo desarrollo durante la primera mitad del siglo XIII ${ }^{57}$. Referente a las parcelas laborables, éstas se desarrollan en las zonas más alejadas de la ciudad, desde el Pla hasta el Vallès, desde el Llobregat hasta el Penedès. Se trata de tierras que presentan un interés económico menor, pero que son los verdaderos orígenes de una cultura cerealística. Su desarrollo tiene lugar a partir de la segunda mitad del siglo XII y se mantendrá, con altibajos, durante todo el siglo XIII. Paralelamente entre la primera y la segunda mitad del siglo XII es cuando se desarrollan las masías, que permiten identificar con seguridad las explotaciones campesinas.

\footnotetext{
${ }^{53} \mathrm{G}$. DUBY, Economia, op. cit.

${ }^{54}$ R. VIADER, Autour, op. cit. cuadros 1 y 6.

${ }^{55}$ J.E. RuIz DOMÈNEC, The urban, op. cit.

${ }^{56}$ En este período se produce un descenso en la venta de tierras en el territorio y los suburbios de Barcelona. Además si la modiata de viña por término medio entre los años 1060 y 1080 era de 114 sueldos, los precios medios entre 1090 y 1140 será de 39 sueldos, por tanto había perdido dos terceras partes de su valor. S.P. BENSCH, Barcelona, op. cit., cuadros 3.1 y 3.2 pp. 92 y ss.

${ }^{57}$ R. VIADER, Autour, op. cit., cuadro 2.
} 
Durante el siglo XII se desarrolla otro fenómeno, el cual se había iniciado tímidamente un siglo antes. Se trata de un comercio activo, con salida y llegada en Barcelona de productos y mercancias. Así, entre 1105 y 1130 , la ciudad establece contactos directos con los puertos italianos y buena prueba de ello es la expedición militar a Mallorca del año $1113^{58}$. Este desarrollo es observado por Benjamín de Tudela que en un viaje iniciado en 1160 por diversas lugares del Mediterráneo menciona que Barcelona es una urbe pequeña y hermosa situada a las orillas del mar, y a cuyo puerto acuden con mercancías comerciales de todas partes, desde Grecia, Pisa, Génova, Sicilia, Alejandría de Egipto, Tierra Santa, África y todos sus aledaños ${ }^{59}$. Por tanto puede plantearse como hipótesis que ya en el siglo XII empiezan a llegar a la ciudad alimentos cerealísticos procedentes de otros puertos mediterráneos. También hay que destacar que en la segunda mitad del siglo XII se inicia un nuevo sistema dentro del crédito barcelonés: el préstamo marítimo.

\section{MORTALIDADES VIOLENTAS}

Si bien las crisis alimentarias fueron comunes en toda la Edad Media, las mortalidades a consecuencia de la violencia fueron numerosas antes del año 1000. El período que abarca desde el año 801 hasta el 1200 es testigo de gran número de destrucciones de casas, cosechas y el cautiverio de muchos pobladores.

El punto de partida es sin duda la conquista franca de Barcelona en el año 801, la ciudad cae después de un sitio de 7 meses. De hecho son continuas devastaciones producidas a lo largo del siglo IX. En el año 827 los musulmanes procedentes de Zaragoza queman los campos de Barcelona y Gerona: "... vastatis Barcinonensium ac Gerundensium agris, villisque incensis, cum incolumi exercitu Caesaraugustam se prius reciperet, quam a Francorum exercitu potuisset vel videri"60. En el 852 tienen lugar nuevas

\footnotetext{
${ }^{58}$ P. BonNASSIE, Catalunya, op. cit., II, p. 279.

${ }^{59}$ I. GoNZÁLEZ Llubera, Viaje de Benjamín de Tudela 1160-1173. Madrid, 1918, p. 52.

${ }^{60} \mathrm{~J}$. BALARI I JOVANY, Orígines, op. cit., I, p. 306.
} 
incursiones y devastaciones de Barcelona, situación que vuelve a producirse en el año $914^{61}$.

Pero tal vez la destrucción más importante es la que se produce en el año 985 con Almanzor. Por la importancia que dan tanto los documentos privados como las crónicas puede pensarse que, en este momento, Barcelona debía haber gozado de una época de estabilidad, experimentando a lo largo del siglo X un importante desarrollo económico, urbano y demográfico. Los sucesos empiezan a principios de mayo con la salida de Córdoba del ejército musulmán y con el inicio del sitio a Barcelona en el primer día de julio. La caída se produce después de 6 días. Las consecuencias del asalto fueron terribles pues si bien la mayoría murieron en la defensa, una gran parte de la población fue esclavizada y llevada a Córdoba. En este sentido se ha hecho balance numérico de las personas muertas, desaparecidas y cautivas ${ }^{62}$. También se han estudiado con detenimiento las destrucciones ocasionadas en Sant Cugat ${ }^{63}$. No sólo fueron los defensores cristianos los más perjudicados, también la comunidad judía de Barcelona fue exterminada y sus bienes incorporados al patrimonio condal ${ }^{64}$.

Los documentos mencionan que Barcelona fue entre otras cosas: "obsessa", "apprehensa", "deprehensa", "capta", "destructa", "dissipata", "devastata", "depopulata". También los documentos recuerdan que: "periit", "interiit", "periclatavit". Por último se describe la: "obsessio", "intericio", "interitus", "submersio", "exterminacio", "captio", "capitivitas", "interruptio" de la ciudad ${ }^{65}$.

\section{CRONOLOGÍA, INTENSIDAD DE LAS CRISIS Y ALTURAS DE LA POBLACIÓN}

Hay que partir del principio que, para esta época, las crónicas no dicen prácticamente nada sobre hambrunas y mortandades y las pocas noticias

\footnotetext{
${ }^{61}$ A. Aulestia I PijOAN, Barcelona ressenya histórica, Barcelona, 1878, pp. 14-15.

${ }^{62}$ M. RovirA, Notes, op. cit., pp. 33-35.

${ }^{63} \mathrm{G}$. FELIU, Al-Mansur, op. cit.

${ }^{64}$ ACA. R. Borrell II, núm. 45.

${ }^{65}$ M. ZIMMERMANN, La presa, op. cit., pp. 75 y 76.
} 
que aparecen son realmente muy escuetas. Se han de buscar otras formas para poder localizar y analizar las diferentes crisis. Con anterioridad se ha mencionado que la información procede principalmente de los documentos privados. Estos datos, complementados con algunas referencias cronísticas, permiten configurar el mapa cronológico de las diferentes crisis de mortalidad acaecidas en Barcelona.

En los siglos IX y X se dan muchos períodos de penurias. En todo caso sólo puede hablarse de crisis violentas. Además de las destrucciones de los años 801 y 852, documentalmente aparecen las primeras referencias poco antes del 875, Carlos el Calvo envía una cierta cantidad de dinero al obispo de Barcelona, Frodoí, para que pueda restaurar la catedral. Tres años más tarde, a petición del obispo de Barcelona, Luis el Tartamudo confirma los privilegios y bienes concedidos por Carlos a la iglesia de Barcelona, autorizándole para que restaure su canónica prácticamente destruida ${ }^{66}$.

En el año 985 se produce la gran destrucción de Barcelona. Un elevado número de documentos privados y crónicas dejan constancia de este episodio, siendo significativo el hecho que los ecos de esta destrucción alcanzan hasta los primeros años del siglo $\mathrm{XI}^{67}$.

Para el siglo XI se citan diversos años de crisis. El cronista Pere Miquel Carbonell dice, refiriéndose al año 1006: "e sia memòria, con en temps d'aquest predit rey, ço és en l'any mil e sis, fam e mortalitat tan forment cresqué e pres quasi tot lo mon, que los vius, per gran treball e ahuix de soterrat los morts en tanta multitut, morien. Tan gran fonch aquesta pestilencia, que entre aquells qui moriren per fam e aquells qui moriren per epidémia, de cent personas no $n$ nasqueren deu"68.

En el año 1018 hubo una gran carestía en todo el territorio de Barcelona que obliga a muchos hombres a marcharse a otras zonas ${ }^{69}$.

\footnotetext{
${ }^{66}$ A. FÀBrega I GraU, Diplomatari, op. cit., núms. 2 y 3.

${ }^{67}$ Entre las crónicas más importantes que recogen la caída de Barcelona en el año 985 se encuentra: Crónica Skokloster, Chronicon barcinonense I, Chronicon barcinonense II, Crónica de Sant Cugat, Chronicon alterum rivipullense, Chronique de Saint Victor de Marseille. Muchas de ellas han sido estudiadas por M. ZIMMERMANN, La presa, op. cit.

${ }^{68}$ A. Alcoverro, Cronica, op. cit., I, p. 248.

${ }^{69} \mathrm{ACB}, \mathrm{LA}, \mathrm{II}$, núm. 521.
} 
En el 1033, Guadalt, obispo de Barcelona, hace donación de tierras, con la condición que se construyan torres y muros por la necesidad que tiene la ciudad en su defensa ${ }^{70}$.

Una nueva carestía aparece en el año 1039. Incluso se menciona que algunos habitantes estaban obligados a comer las hierbas del campo ${ }^{71}$.

En el 1043 por necesidades del hambre que ha causado el mal tiempo, Llobet y su hijo Pons se ven obligados a vender unas casas y tierras situadas en el término de Tarrassa a cambio de 7 éminas de cebada ${ }^{72}$.

Las crisis derivadas de las guerras se hacen patentes en el año 1057, tal como se menciona en un documento de donación de una tierra que fue propiedad de un hombre llevado en cautividad ${ }^{73}$.

Antes de llegar al año 1060 tuvo lugar una hambruna generalizada por toda la región del Bages: "fuit grande necessitas fame per totam nostram regionem". Tanto es así que Bonhom tuvo que vender a una mujer llamada Denia y a sus hijos la mitad de un molino, de una viña, de huertos y de un campo situados en los términos del castillo de Copons, a cambio de 10 sestercios de cebada, 5 cuarteras de trigo y 7 cuarteras de vino prestado durante el año de la escasez ${ }^{74}$.

Entre los años 1065 y 1066 tiene lugar otra gravísima mortalidad. En un documento privado de enero de 1066 se menciona que Gerberga y su hijo han de vender sus pertenencias debido a las necesidades y hambres ${ }^{75}$. También se dice que esta grave situación la padecen otros vecinos, hecho que se comprueba cuando varios días después Riquilda y sus hijos han de vender una casa a Bonfill Guillem, a causa del hambre que padecen ${ }^{76}$.

\footnotetext{
${ }^{70} \mathrm{ACB}$, LA I, núm. 380.

${ }^{71} \mathrm{ACB}, \mathrm{LA}$ II, núm. 247.

${ }^{72}$ J. Alturo i Perucho, L'arxiu, op. cit., núm. 48.

${ }^{73} \mathrm{ACB}$, LA II, núm. 423.

${ }^{74} \mathrm{ACA}, \mathrm{RB}$ I, núm. 246.

${ }^{75} \mathrm{ACB}, \mathrm{LA}$ I, núm. 286.

${ }^{76} \mathrm{ACA}, \mathrm{RB}$ I, núm. 339.
} 
En el año 1084, aparece una referencia aislada en la zona del Vallès, por el cual Adalbert y su mujer Ega, a causa de la necesidad y por el hambre tienen que vender, por 18 sueldos, un alodio situado en Terrassa ${ }^{77}$.

Tal vez la primera gran crisis cerealística que de forma contrastada aparece en Barcelona - pero además extendida a muchos lugares de la Cataluña cristiana - tiene lugar entre los años 1092-1094. Se trata de una hambruna que traspasó las fronteras del Principado, hasta el punto que se señala en las crónicas que hubieron: "magnas fames in toto mundo ${ }^{178}$. Incluso 20 años más tarde aún se recordaba esta crisis ${ }^{79}$. De hecho esta es una de las pocas hambrunas altomedievales en las que aparecen gran número de referencias. Paralelamente coincide con un declive familiar y económico iniciado hacia 1080 y que había de durar unos 15 años ${ }^{80}$.

Para el siglo XII el número de carestías se reduce considerablemente en lo que se refiere a la ciudad y el territorio de Barcelona. Hacia 1108 los almorávides sitiaron Barcelona durante 2 días, y si bien no hay constancia de graves destrucciones en la ciudad si fueron atacados territorios cercanos ${ }^{81}$.

En el año 1124 el matrimonio formado por Adelaida y Ramon Sendret, a causa del hambre que padecen, tienen que vender una tierra situada en Sants por el precio de 7 morabatines $^{82}$.

En 1130 se menciona que la iglesia de Valldoreix había quedado destruida y además se había convertido en un lugar inhabitable, a causa de las frecuentes incursiones de los paganos ${ }^{83}$.

${ }^{77}$ P. PUig I USTREll, El monestir, op. cit., núm. 464.

${ }^{78}$ Cronicon altera Rivipullense (a). J.L. VillanUeVA, Viage, op. cit., p. 246.

${ }^{79}$ En el 1116 Salomó Arimany y su mujer Maria donaron a su hijo Guifré una casa situada en el suburbio de Barcelona, en compensación de la ayuda prestada con ocasión del hambre que había habido en Barcelona y que sólo fueron socorridos por Dios y por su hijo Guifré. ACA, RB III, núm. 191.

${ }^{80}$ J.E. RUIZ DOMÈNEC, Solidaridad, op. cit., p. 20.

${ }^{81} \mathrm{ACB}$, LA II, núm. 123, "...sequenti vero tempore exercitus magnus moabitarum qui biduo Barchinonam civitatem obsedit, ipsam ecclesiam volavit et altare suffodit et fregit".

${ }^{82}$ ACB, LA I, núm. 419.

${ }^{83} \mathrm{ACB}$, LA III, núm. 235, "ipse quippe locus et ecclesia iam destructa est et inhabilitatis facta est propter frequentem paganorum incursiones, et qui remansit iam dispersus est per multas ecclesias". 
En el año 1131 Ramon Seguí, su mujer Ermessenda y su hijo Pere acuerdan con Bernat Otger una concordia sobre la posesión de una tierra a causa de su gran necesidad ${ }^{84}$.

En 1140 se vuelve a mencionar una carestía cuando Bertan de Fiol tiene que vender, por el precio de 3 sueldos, una tierra situada en Rexach, a causa de la hambruna ${ }^{85}$. También en este año se concede un molino a cambio de la cesión anual de cebada y además se han de construir casas y muros para defenderse de los musulmanes ${ }^{86}$.

Ya entre los años 1146-1147 se cita una gran crisis de alimentación acompañada de pobreza. De hecho, a causa del elevado número de textos se trató de gran hambruna, tal vez la más importante en el territorio de Barcelona durante el siglo XII. Así Pere Bernat y Prodetta, su mujer, tienen que vender a Pere Ramon una tierra situada al Vallès por la carestía y la miseria ${ }^{87}$. Esta situación también se repite en la parroquia de Sant Pere Rexach en donde Pere Mir y Adelaida han de vender a los canónicos de las iglesias de Barcelona una tierra allí situada a causa de la máxima necesidad y hambre ${ }^{88}$. A principios del año 1147 la carestía aún continuaba, cuando Narbona y su hijo Ramon tuvieron que vender a la Seo de Barcelona una viña situada en Matabous a causa de la miseria y el hambre que padecen ${ }^{89}$.

Según la Crónica General de España en el año 1172 "y en aquest tems mateix, en lo mes de noembre, fo feta gran inundació... absorbí tot lo qui era sembrat, per què en lo prop següent any se seguí molt gran fam". Continua diciendo "en aquest tems mateix, fam inextimable fouch majorment a Gal·lia, per lo qual, a sosteniment dels pobres foren venuts y empenyorats los ornaments de les esglésies"90. También las crónicas mencionan que en este

\footnotetext{
${ }^{84}$ En todo caso, la presencia de los cónsules de Barcelona para testificar el acuerdo puede dar a entender que se trata de una necesidades particulares, no extrapolables a la generalidad del territorio. ACB, LA II, núm. 447.

${ }^{85} \mathrm{ACB}, \mathrm{LA}$ I, núm. 826.

${ }^{86} \mathrm{ACB}, \mathrm{LA}$ IV, núm. 1508.

${ }^{87} \mathrm{ACB}, \mathrm{LA}$ I, núm. 874.

${ }^{88} \mathrm{ACB}$, LA II, núm. 725.

${ }^{89} \mathrm{ACB}$, LA III, núm. 181.

${ }^{90}$ A. Alcoverro, Cronica, op. cit., vol. II, pp. 39 y 40.
} 
año se producen: "magnas fames in terra"91. En todo caso, no se ha encontrado ninguna evidencia documental privada que confirme esta hambruna en el territorio de Barcelona.

En 1184 se meciona que el hambre se extendió a muchos reinos hispánicos e incluso que el propio rey Alfonso pudo comprobar el alcance de la mortalidad: "e quant hagué complit son vot e sa promissió, e los més dels reys de Hispania inclinats e induïts a pau e concòrdia, torna-sse' $n$ en sa terra, en la qual havia gran carestía e les gents morien de fam y extene's aquesta fam a quasi tot lo mon, e lo predit rey Ildefons, mogut de pietat e de misericordia, en honor de nostre senyor Déu, visita la su tırra é féu gran bé a molta gent qui morie de fam" ${ }^{\prime 2}$. Esta carestía también se ve reflejada en los documentos privados. El 4 de noviembre, Pere Pons tiene que vender a Guillem Pons una tierra situada en el Cogoll por 62 sueldos a causa de su gran pobreza ${ }^{93}$. Posteriormente en 1185 hace donación de sus bienes a la Seo de Barcelona encontrándose oprimido, famélico y desnudo ${ }^{94}$. En septiembre el rey confirma esta donación por razón que Pere Pons ha elegido servir a Dios y a la Iglesia de Barcelona a causa de su pobreza y hambruna ${ }^{95}$.

Por último, en 1194, un documento privado habla específicamente de tiempo de carestía: Ermesenda, viuda de Pere Bruni, y sus hijas venden unas tierras situadas en Santa Eulalia de Pronveçana ${ }^{96}$.

Las crisis de carestía se extendieron prácticamente a lo largo del siglo XI y XII y, por tanto, se ha de pensar que en momentos concretos la población pasó graves necesidades alimentícias. Igualmente cabe preguntarse si en aquellos años en que no hubieron hambrunas, el nivel de nutrición fue suficiente como para satisfacer las necesidades de la población.

Para contestar a esta pregunta hay que utilizar otro tipo de información, concretamente, los resultados observados en las excavaciones arqueológicas y en especial los datos antropométricos deducidos de las alturas de la población. Las series temporales sobre alturas son uno de los indicativos más

${ }^{91}$ Cronica Dertusense II (a). J.L. VIllanueva, Viage, op. cit., p. 239.

${ }^{92}$ A. Alcoverro, Cronica, op. cit., vol. II, p. 39.

${ }^{93} \mathrm{ACB}, \mathrm{LA}$ I, núm. 198.

${ }^{94} \mathrm{ACB}, \mathrm{LA}$ I, núm. 65.

${ }^{95} \mathrm{ACB}, \mathrm{LA}$ I, núm. 62.

${ }^{96} \mathrm{ACB}, \mathrm{LA}$ I, núm. 1026. 
fidedignos para conocer los cambios demográficos en la población, mejor que el conocimiento de los salarios reales ${ }^{97}$. Además son datos que indican con precisión la manutención de un colectivo humano. De hecho este análisis representa una estimación muy fiable del nivel de nutrición de los alimentos consumidos $^{98}$.

Fisiólogos y antropólogos han podido valorar los efectos de las carestías alimentarias en el crecimiento humano. Por tanto, su conocimiento puede dar nuevos datos a las crisis alimentarias medievales. Se dispone de una serie de resultados aportados por los restos arqueológicos excavados en el Maresme, Baix Llobregat y el Vallès occidental, correspondientes a los siglos VI al XIII ${ }^{99}$. Se trata por tanto de restos humanos que habían vivido cerca de Barcelona y que en buena medida fueron influenciados por su radio de acción. Vives ha estudiando más de 30 excavaciones arqueológicas en la Cataluña altomedieval y ha podido deducir unas alturas medias para hombres y mujeres. Concretamente ha establecido en 165,80 centímetros para los hombre y 154,01 para las mujeres. Era la altura que tenía la población que habitaba en el litoral, el interior y la zona montañosa. Comparativamente se trata de valores un tanto alejados de los encontrados para los pobladores visigóticos. Así, para este grupo étnico se han encontrado alturas superiores; para los hombres 167,61 centímetros y, 154,41 para las mujeres ${ }^{100}$. Se ha apuntado como posible causa una nutrición más variada y rica en proteínas y vitaminas gracias al acceso a un medio boscoso como debía haber ocurrido en los primeros siglos medievales y que los datos polínicos han confirmado para la zona del litoral barcelonés ${ }^{101}$.

Referente a las diferentes tumbas humanas excavadas en el territorio de Barcelona, la primera se encuentra situada en Santa María de Martorell y cronológicamente comprende los siglos VI al XIII. Se trata de un monasterio

\footnotetext{
${ }^{97}$ R.W. FOGEL, Cambios seculares en la estatura y la nutrición en Estados Unidos y Gran Bretaña, en El hambre en la historia. El impacto de los cambios en la producción de alimentos $y$ los modelos de consumo sobre la sociedad, Madrid, Editorial Siglo XXI, 1990, p. 272, nota 1.

${ }^{98}$ R.W. FOGEL, Cambios, op. cit., p. 274.

${ }^{99}$ E. VIVES, La población, op. cit., pp. 72 y ss.

${ }^{100}$ T.A. VALERA, Estudio antropológico de los restos óseos procedentes de necrópolis visigodas de la Península Ibérica. "Trabajos de antropología", XVIII/2,3 y 4 (1974-1975), pp. 7-157. E. VIVES, La població, op. cit., p. 104.

${ }^{101}$ E. VIVES, La població, op. cit., p. 104.
} 
construido en las épocas paleocristiana y románica. Referente a las alturas de los restos encontrados se observa que los hombres tenían unas elevaciones que variaban entre los 160 y los 180 centímetros, mientras que las mujeres se sitúan entre los 150 y los 154 centímetros. Se trata pues de esqueletos con diferencias numéricas muy contrastadas y por tanto de difícil explicación ${ }^{102}$.

Una segunda necrópolis se encuentra situada al lado de la iglesia de la Mare de Déu de Bellvitge, en el Baix Llobregat. Son enterramientos datados desde la segunda mitad del siglo I hasta principios del siglo XII. Es un área de tumbas infantiles, si bien también se encuentra una sepultura amplia que puede sugerir una grave mortalidad, una crisis que pudo obligar a realizar una fosa precipitada para enterrar los cadáveres.

En los enterramientos situados en la población de Sant Nicolau, en el Vallès occidental, aparece una necrópolis donde están enterrados individuos con alturas moderadas, en su conjunto disponen de alturas parecidas a las de la Tarragona tardorromana, es decir entre los 163.18 centímetros para los hombres y los 151,82 para las mujeres.

Por último se encuentra la necrópolis de Montjuïc. Se trata de un conjunto de 171 sepulturas de las cuales se han obtenido los restos de 114 individuos. En todo el material descubierto por la excavación no hay ninguna referencia a una fecha concreta, si bien algunas lápidas estudiadas dan fechas comprendidas entre los siglos XI y XIII ${ }^{103}$. Ésto no impide que también se encuentren algunos enterramientos del siglo XIV. Las estaturas deducidas son para los hombres 161,95 centímetros y para las mujeres 149,10 . Se han podido establecer 5 grupos de alturas tanto para el sexo masculino como para el femenino. Identificando las elevaciones igual o menor a la media catalana medieval resulta que éstos representan el 73 por 100 para los hombre y un 70 por ciento para las mujeres. Son pues estaturas medias bastante bajas ${ }^{104}$.

Se pueden comparar todos estos datos con la media general de alturas de los habitantes de la Cataluña altomedieval, deduciéndose que son valores menores. En consecuencia la nutrición en Barcelona y su territorio a lo largo de la alta Edad Media fue bastante deficitaria. Esto coincidiría con un

\footnotetext{
${ }^{102}$ E. VIVES, La població, op. cit., pp. 74 y ss.

${ }^{103}$ M. CANTERA-J.M M Millás, Inscripciones, op. cit.

${ }^{104}$ M. y A. Prevosti, Restos, op. cit.
} 
panorama de crisis agrarias y alimenticias bastante permanente desde el siglo $\mathrm{X}$, dándose la circunstancia que la riqueza en la alimentación no debió de alcanzar niveles aceptables, como sí ocurrió en otros territorios.

\section{CONCLUSIONES}

Llegados a este punto se pueden establecer de una serie de conclusiones sobre mortalidades, crisis y alimentación en el territorio de Barcelona entre los años 801 y 1200 . Ante todo se observa que la base de la alimentación a partir del siglo XI fueron los cereales y por tanto poca importancia tuvieron la caza, los frutos silvestres y la ganadería. Antes de esta fecha se hace difícil conocer con exactitud a través de las fuentes documentales el modelo de consumo. Las crisis de subsistencia junto a las crisis de mortalidad, tendrán repercusiones a la largo plazo en la morfología de la población.

Las continuas crisis de carestía que tienen lugar en Barcelona desde principios del siglo XI serán una realidad a lo largo del del siglo XII. Por tanto para la alta Edad Media no puede hablarse de la consolidación de la agricultura en el territorio de Barcelona, como mínimo como para satisfacer las necesidades de una población demográficamente en expansión.

Se ha puesto de manifiesto que el hambre en general no tuvo efectos negativos ya que incitó a los hombres a producir más. Incluso la lucha contra la carestía es el primer motor de la expansión agrícola medieval. Pero esta necesidad también obliga a producir mejor y a perfeccionar las técnicas y prácticas agrícolas introduciendo mejoras en el utilaje ${ }^{105}$. Podemos por tanto pensar que las carestías agrarias de la población de Barcelona y de su territorio durante el siglo XI ayudó a que se produjera una mejora sustantiva en la producción agrícola de cereales, tal como se verá a partir de la segunda mitad del siglo XII.

Las continuadas crisis de subsistencia que asolan Barcelona desde el siglo XI, puede que ayudaran a la fundación, a partir del año 1161, de las primeras Almoinas permanentes en la ciudad. Concretamente, se parte del concepto de que a los pobres se les ha de alimentar diariamente. Hay pues una

${ }^{105}$ P. BONNASSIE, Consommation, op. cit., p. 1050. 
toma de conciencia que existe un sector de la población que no puede subsistir sin ayuda externa ${ }^{106}$.

No se puede saber con exactitud cual fue la participación del comercio de granos como solución a las diferentes crisis alimentarias acaecidas en Barcelona durante este período. En cambio, sí se sabe con seguridad la importancia que tiene el puerto y la llegada de barcos con mercancías, documentado desde principios del siglo XII.

${ }^{106} \mathrm{~J}$. BAUCELlS, La Pia Almoina de la Seo de Barcelona origen y desarrollo, en "A pobreza e a assistência aos pobres na Península Ibérica durante a Idade Média". Actas das $1{ }^{\text {as }}$ Jornadas Luso-Espanholas de História Medieval, Lisboa. 25-30 septembro de 1972, p. 88. 


\section{APÉNDICE DOCUMENTAL ${ }^{1}$}

1018, octubre, 21.

Espaciosa y su hijo Bonhom venden una tierra situada al condado de Barcelona, en el Vallés, en el término de Rexach, por un mancuso y cuatro sueldos, a causa de su necesidad.

ACB, LA II, núm. 521

"... pro ipsa necessitate qui fui in ipso anno quando homines exierunt de comitatu Barchinone et fuerunt in alias regiones..."

1039, febrero, 23.

Ermetrui y su hija Bonadona venden a Gerbert, presbitero, un herranal situado en el territorio de Barcelona, en la parroquia de Sant Andreu, en el término de Vilapiscina, por una cuartera y media de cebada a causa de la necesidad que padecen.

ACB, LA II, núm. 247

"... non aberit michilque manducare neque bibere nisi erbas de ipsos campos...."

${ }^{1}$ En el apéndice únicamente se relacionan los documentos que versan sobre las crisis de cereales. No hay ninguna referencia a las crisis violentas, debido a que muchos de estos textos han sido frecuentemente publicados. 
1043, febrer, 13.

Llobeta y su hijo Pons, tienen que vender unas casas y unas tierras situadas en el condado de Barcelona, en el término de Tarrassa, por 7 éminas de cebada, a causa del hambre provocado por el mal tiempo.

ADB, SEC, perg. 109

"...propter necessitatem famis per persecucione petrarum..."

1060, febrero, 9

Bonhom vende a Denia y a sus hijos la mitad de un molino, la mitad de una viña plana y la mitad de unas tierras, situadas en el condado de Manresa, en el Castell de Copons, por el precio de 10 sestercios de cebada, 5 cuarteras de trigo y 7 quarteras de vino, que fue dado en el año en que hubo una gran hambruna por toda la región.

ACA, RB I. núm. 246

"... in ipso anno quando fuit grande necessitas fame, per totam nostram regionem..."

1066, enero, 3 .

Gerberga y sus hijos venden a Pere Seniofret, sacerdote, una casa y sus pertenencias, situadas en la ciudad de Barcelona, dentro de los muros, por 21 mancusos de oro, a causa de la gran necesidad y miseria que pasan ellos y sus vecinos.

ACB, LA I, núm. 286 
"...facimus autem hec propterea quia cogit nos magnas famis necessitas atque inopia et cuncte nostre utilitatis nobis profuture indigencia atque penuria universis nostris vicinis et terris omnibus valde nota..."

1066. enero, 9.

Riquilday sus hijos Bernat, Guilla, Gerberga, Remaneat, y Arsenda venden una casa a Bonfill Gilmon y a su mujer Natàlia, por 2 onzas de oro de Barcelona, a causa del hambre que padecen.

ACA, RB I, núm. 339

"...Propterea nos prenominati, mortali languore famis et sitis atque frigoris vexati sive compressi..."

1084, mayo, 20.

Adalbert y su mujer Ega venden al monasterio de Sant Llorenç, un alodio, situado en el condado de Barcelona, en Mur, por 18 sueldos en moneda de Barcelona, a causa del hambre.

ACA, Monacales, Sant Llorenç de Munt, núm. 221

"...pro necesitas fame..."

1092, diciembre, 22.

Petronila vende a Ramon Llopart y a Bernat Otger tres cuartas partes de una casa situada en el suburbio de Barcelona, al lado de los muros, por 25 mancusos de oro, a causa del hambre.

ACB, $1-4-311$ 
"...anc namque vendicionem necessittate famis vobis facio, ne ego et filii mei fame intoleribili moriamur".

1094, enero, 15.

Bonfill Esteve cede a la Seo de Barcelona, por período de un año, el usufructo de su alodio a cambio de que la canónica le mantenga y le vista, a causa de la gran calimidad que padece.

ACB, LA I, núm. 409

"...ingruente inedie nimia calamitate..."

1094, marzo, 1.

Guillem Bonfill y su mujer Nevia venden un alodio situado en el territorio de Barcelona, en el lugar llamado Clot de la mel, cerca de los muros antiguos, por 74 mancusos, a causa de la pobreza y el hambre.

ACB, LA I, núm. 496

"...propter inipiam famis ut unde vivamus nos et infante nostri..."

\section{1}

1094, mayo 19.

Onofret, Guillem y Domenech Bernat venden a Pere Umbert unas viñas situadas en el territorio de Barcelona, en Esplugues, por 30 onzas de oro, a causa de su gran necesidad.

ACB, LA IV, núm. 121

"... deinde cogente nimia necessitate..." 
1124, abril, 18 .

Adelaida y Ramon Sendret venden a Bernat Berenguer y a Ermessenda, su mujer, unas tierras llamadas "Llobet", situadas en el territorio de Barcelona, en Sants, a causa del hambre.

\section{ACB, LA I, núm. 419}

"... necessitatem fame..."

1131, enero, 21.

Ramon Seguí, su mujer Ermessinda y su hijo Pere acuerdan ceder a Bernat Otger y a su hijo Pere unos alodios a cambio de 1 morabatín, a causa de su gran necesidad.

ACB, LA II, núm. 447

"...in magna eorum necessitate..."

1140 , diciembre, 18.

Bernat de Fiol vende a Bernat de Ripollet un alodio situado en la parroquia de Sant Pere, en Rexach, por 3 sueldos, a causa de la hambruna que padecen.

ACB, LA I, núm. 826

"... pro necessitate famis..." 
1146 , enero, 6.

Pere Bernat y su mujer Predeta, venden a Pere Ramon una parte de una tierra, situada al Vallès en la parroquia de Sant Ciprià de Cabanyes, en un lugar llamado "Torel", por cuatro sueldos y medio, a causa de la pobreza y del hambre.

ACB, LA I, núm. 874

"... pro necessitate fame et in opie..."

1146, abril, 7.

Pere Mir de Rexach, y su mujer Adaleda junto a Bernat de Venteiag y su mujer Arsenda, venden a Bernat Ros, canónigo de la catedral de Barcelona, una tierra situada en el condado de Barcelona, en el Vallés, en la parroquia de Sant Pere de Rexach, en un lugar llamado "Mulnar", por 5 morabatines de oro, a causa del hambre.

ACB, LA II, núm. 725

"... pro hac venditione in maxima necessitate famis..."

1147, enero, 7.

Narbona y su hijo Ramon, venden a Bernat Rubi, clérigo y canónigo de la catedral, una tierra situada en Matabous, por un morabatín, a causa de su gran necesidad y por la miseria que sufren.

ACB, LA III, núm. 181

"... pro magna necessitate famis et in inopie quam patimur..." 
1184, noviembre, 4 .

Pere Pons vende a Pere de Ripoll una porción de tierra, situada en el territorio de Barcelona, en el Cucull Antic, a causa de su gran pobreza.

ACB, LA I, núm. 198

"...nimia pauperitate et inope a opressus..."

1185, junio, 13.

Pere Pons, pobre, hace donación a la Seo de Barcelona de la casa y de todas las pertenencias que posee.

ACB, LA I, núm. 65

"... magna pauperitatis famis ac nuditatis oppressus..."

1194, junio, 13

Ermessenda, viuda de Pere Bruny, junto a sus hijas Guilleuma, Saurina, Maria y Joana, venden tres porciones de tierra situadas en el territorio de Barcelona, en la parroquia de Santa Eulàlia de Provençana, en un lugar llamado "Expodiola", a causa de su pobreza, el hambre y la necesidad.

ACB, LA I, núm. 1026

"...pro magna necessitate famis et pauperatis quam patimur tempore carestie...". 


\section{RÉSUMÉ}

Pendant le haut moyen âge la ville et le territoire de Barcelone ont souffert de profondes crises agraires qui ont atteint de larges groupes humains. L'on aborde la relation existante entre le paysage agraire, l'alimentation et la mortalité, et l'on arrive à la conclusion que, malgré son caractère de territoire en expansion aussi bien économique que démographique, la zone comprise entre les fleuves Besòs et Llobregat a connu un niveau de nutrition plus déficient que d'autres endroits de la Catalogne.

\section{SUMMARY}

During the Early Middle Ages the city and the area of Barcelona suffered deep agrarian crises which affected large human groups. The study approaches the existing relationship between agrarian landscape, nourishment and mortality, and it comes to the conclusion that, despite its economical and demographical prosperity, the area comprised between the Besòs and Llobregat rivers kept a poor level of nutrition in comparison with other areas in Catalonia. 